Article

\title{
Differences in Aluminium Accumulation and Resistance between Genotypes of the Genus Fagopyrum
}

\author{
Benjamin Klug ${ }^{1}$, Thomas W. Kirchner ${ }^{2}$ and Walter J. Horst ${ }^{2, *}$ \\ 1 Aglukon Spezialdünger GmbH \& Co. KG, Düsseldorf; Germany; \\ E-Mail: Benjaminklug@aglukon.com \\ 2 Institute of Plant Nutrition, Leibniz Universität Hannover, Germany; \\ E-Mail: kirchner@pflern.uni-hannover.de \\ * Author to whom correspondence should be addressed; E-Mail: horst@pflern.uni-hannover.de; \\ Tel.: +49-511-762-2627; Fax: +49-511-762-3611.
}

Academic Editor: Gareth Norton

Received: 22 June 2015 / Accepted: 20 August 2015 / Published: 28 August 2015

\begin{abstract}
Aluminium (Al) toxicity is a major factor reducing crop productivity worldwide. There is a broad variation in intra- and inter-specific Al resistance. Whereas the $\mathrm{Al}$ resistance mechanisms have generally been well explored in Al-excluding plant species, $\mathrm{Al}$ resistance through $\mathrm{Al}$ accumulation and $\mathrm{Al}$ tolerance is not yet well understood. Therefore, a set of 94 genotypes from three Fagopyrum species with special emphasis on F. esculentum Moench were screened, with the objective of identifying genotypes with greatly differing Al accumulation capacity. The genotypes were grown in Al-enriched peat-based substrate for 21 days. Based on the Al concentration of the xylem sap, which varied by a factor of five, only quantitative but not qualitative genotypic differences in $\mathrm{Al}$ accumulation could be identified. Aluminium and citrate and $\mathrm{Al}$ and $\mathrm{Fe}$ concentrations in the xylem sap were positively correlated suggesting that $\mathrm{Fe}$ and $\mathrm{Al}$ are loaded into and transported in the xylem through related mechanisms. In a nutrient solution experiment using six selected $F$. esculentum genotypes differing in $\mathrm{Al}$ and citrate concentrations in the xylem sap the significant correlation between Al and iron transport in the xylem could be confirmed. Inhibition of root elongation by Al was highly significantly correlated with root oxalate-exudation and leaf Al accumulation. This suggests that Al-activated oxalate exudation and rapid transport of $\mathrm{Al}$ to the shoot are prerequisites for the protection of the root apoplast from Al injury and thus overall $\mathrm{Al}$ resistance and $\mathrm{Al}$ accumulation in buckwheat.
\end{abstract}


Keywords: aluminum; buckwheat; citrate translocation; genotypic differences; oxalate exudation; tolerance

\section{Introduction}

Acid soils represent a significant percentage of the world's arable lands [1]. Aluminium toxicity is one of the major constrains for crop production on acid soils [2]. Great inter- and intra-species differences exist in Al resistance, which have successfully been exploited for the breeding of better yielding Al-resistant cultivars of crop species on acid, Al-toxic soils [3-5]. The understanding of the physiological and molecular mechanisms underlying Al resistance could contribute to further intensify the breeding of Al-resistant crop cultivars [6,7]. Generally, plant Al resistance may be achieved either through $\mathrm{Al}$ exclusion from uptake and binding in the apoplast of the most Al-sensitive root apex or Al uptake and detoxification within the root symplast, thus Al tolerance [2,8]. For most crop species, Al exclusion through sequestration of Al in the root apoplast with organic acid anions released from the root symplast is the most common mechanism of $\mathrm{Al}$ resistance [9]. Less binding of $\mathrm{Al}$ in the cell walls owing to a lower content of unmethylated pectins [10,11] or hemicellulose [12] of the cell wall may also contribute to $\mathrm{Al}$ exclusion. There is recent evidence that both $\mathrm{Al}$ exclusion and Al tolerance contribute to Al resistance in a coordinated way in Arabidopsis [13] and particularly in the Al-resistant cereal crop rice [14]. In some plant species Al tolerance is combined with the capacity to translocate $\mathrm{Al}$ to the shoots where $\mathrm{Al}$ is accumulated in large concentrations in the leaves $[15,16]$. Among these plant species are tea (Camellia sinensis var. sinensis), buckwheat (Fagopyrum esculentum) and hortensia (Hydrangea macrophylla).

Whereas the physiological and molecular understanding of resistance mechanisms in Al-excluding plant species has made considerable progress in recent years [7,14,17], the understanding of $\mathrm{Al}$ accumulation in relation to $\mathrm{Al}$ tolerance still widely lags behind. The Al accumulator buckwheat is characterized by both, Al exclusion from uptake through Al-induced release by root tips of oxalate [18] and symplastic sequestration of Al by oxalate [19]. Although the role of oxalate release from the roots in $\mathrm{Al}$ exclusion is well established, references [20,21] could not relate differences in oxalate exudation to genotypic differences in $\mathrm{Al}$ resistance between buckwheat genotypes. Comparing genotypes of Fagopyrum tataricum Yang et al. [21] also concluded that root exudation of oxalate could not explain genotypic differences in Al resistance. They suggested that the differences in Al accumulation of root tips were related to differences in cell-wall negativity conferred by lower pectin contents and a higher degree of pectin methylation. $\mathrm{Al}$ accumulation in shoots requires radial transfer of $\mathrm{Al}$ from the root surface to the xylem where $\mathrm{Al}$ is transported primarily as Al-citrate to the shoot [22,23]. Based on sophisticated physiological approaches references [24-26] proposed a hypothesis reconciling $\mathrm{Al}$ exclusion and $\mathrm{Al}$ accumulation in which an $\mathrm{Al}$ oxalate $(\mathrm{Ox})^{+}$ plasma-membrane transporter in the root cortex and a xylem-loading Al citrate $(\mathrm{Cit})^{\mathrm{n}-}$ transporter in the xylem parenchyma cells are key elements of Al tolerance and accumulation in buckwheat.

The aim of the present study was to enhance the physiological understanding of Al exclusion on the one hand and $\mathrm{Al}$ accumulation on the other hand by exploiting differences in Al resistance and 
Al accumulation within a large set of genotypes of the species $F$. esculentum (buckwheat). To even widen the genetic background we included into the genotype selection also genotypes from further species of the Fagopyrum genus namely F. tataricum and F. acutatum.

\section{Results}

Addition of $2-8 \mathrm{~g} \mathrm{Al}_{2}\left(\mathrm{SO}_{4}\right)_{3} \cdot 18 \mathrm{H}_{2} \mathrm{O}$ decreased the $\mathrm{pH}$ of the substrate from 5.6 to 4.0 approximately linearly (Figure 1). In contrast, the soluble and mononuclear Al concentrations increased exponentially from an $\mathrm{Al}$ application of $6 \mathrm{~g}$ on. Neither the $\mathrm{pH}$ reduction, nor the related increase of the soluble $\mathrm{Al}$ in the substrate lead to reduced growth of the plants of the buckwheat cultivar "Lifago" (Figure 2).

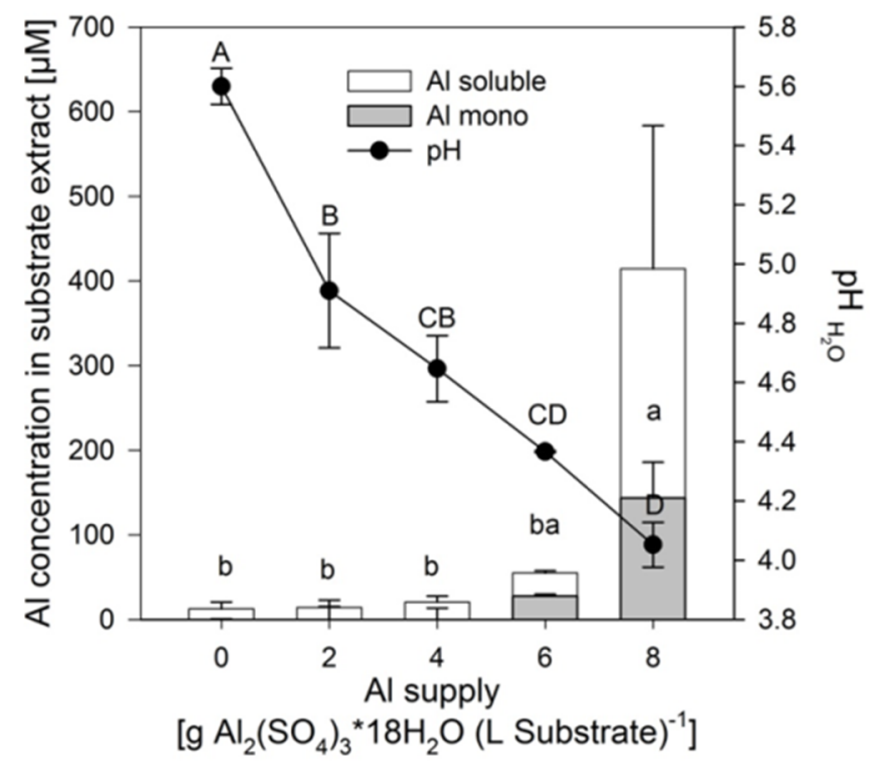

Figure 1. Total soluble, mononuclear $\mathrm{Al}$ ( $\mathrm{Al}$ mono) concentrations and substrate $\mathrm{pH}$ in the aqueous 1:3 $(v / v)$ substrate extract as affected by increasing supply of $\mathrm{Al}_{2}\left(\mathrm{SO}_{4}\right)_{3} \cdot 18 \mathrm{H}_{2} \mathrm{O}$. Bars represent means $\pm \mathrm{SE}, n=3$. Different capital and lower case letters denote differences between treatment durations for $\mathrm{pH}$ values and for $\mathrm{Al}$ mono concentrations, respectively, at $p<0.05$ (Tukey test).

Increasing Al supply did not induce mineral element deficiency-symptoms in shoots of the buckwheat cultivar "Lifago". Also growth, height, and fresh matter of shoots were not significantly affected (Figure 2). There was a tendency of optimum shoot growth at $4 \mathrm{~g}$ Al sulfate supply which was also especially true for root growth (Figure S1). This might indicate a growth-promoting effect of small amounts of $\mathrm{Al}$ in buckwheat.

Although the soluble $\mathrm{Al}$ concentration in the substrate only significantly increased at $8 \mathrm{~g} \mathrm{Al}$ sulfate supply (see above, Figure 1), the Al concentrations in the primary leaves steadily increased from the lowest $\mathrm{Al}$ application rate to reach about $500 \mu \mathrm{g}$ (g dry weight) ${ }^{-1}$ at the highest Al supply (Figure 3A).

Aluminium is readily transported from the roots to the shoots via the xylem typical for Al accumulators. The Al concentration in the xylem sap increased with increasing Al supply to a level of about $400 \mu \mathrm{M}$ at an Al sulfate application of $6 \mathrm{~g}$ (Figure 3A). The xylem-sap citrate-concentration which was more than 10 times higher than the Al concentration increased with the Al supply 
(Figure 3B). In spite of great variability between individual plants, there was a significant positive correlation between $\mathrm{Al}$ and citrate xylem-sap concentrations.

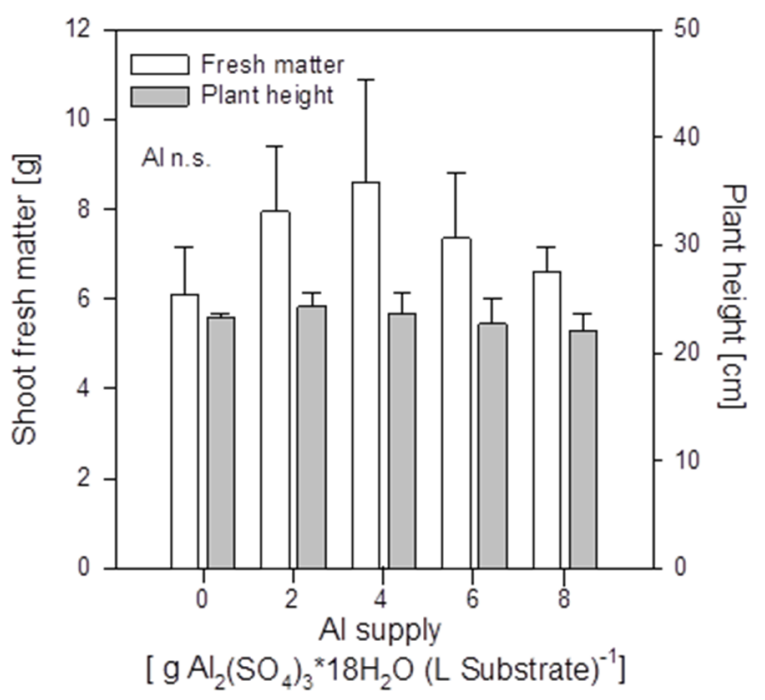

Figure 2. Shoot fresh matter production and height of buckwheat $c v$. "Lifago" plants as affected by increasing $\mathrm{Al}_{2}\left(\mathrm{SO}_{4}\right)_{3} \cdot 18 \mathrm{H}_{2} \mathrm{O}$ supply to the substrate, three weeks after germination. Bars represent means $\pm \mathrm{SE}, n=3$.

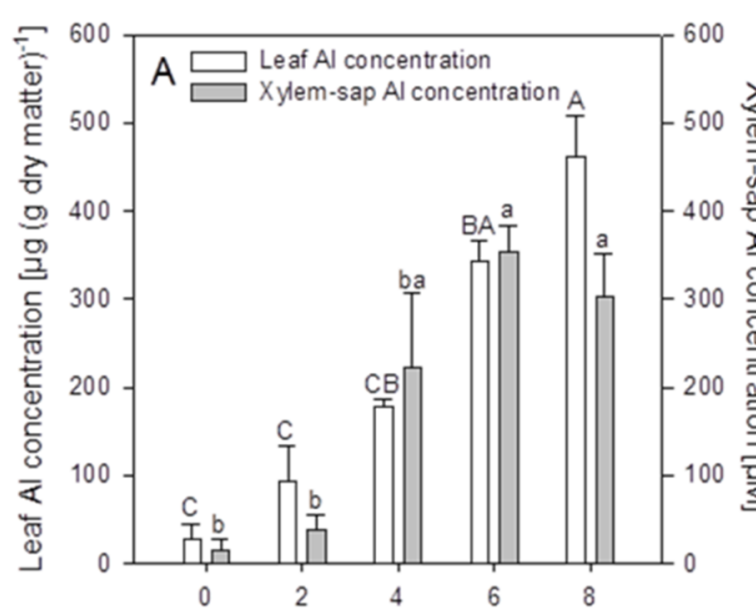

Al supply

$\left.\left[\mathrm{g} \mathrm{Al}_{2}\left(\mathrm{SO}_{4}\right)_{3}{ }^{*} 18 \mathrm{H}_{2} \mathrm{O} \text { (L Substrate }\right)^{-1}\right]$

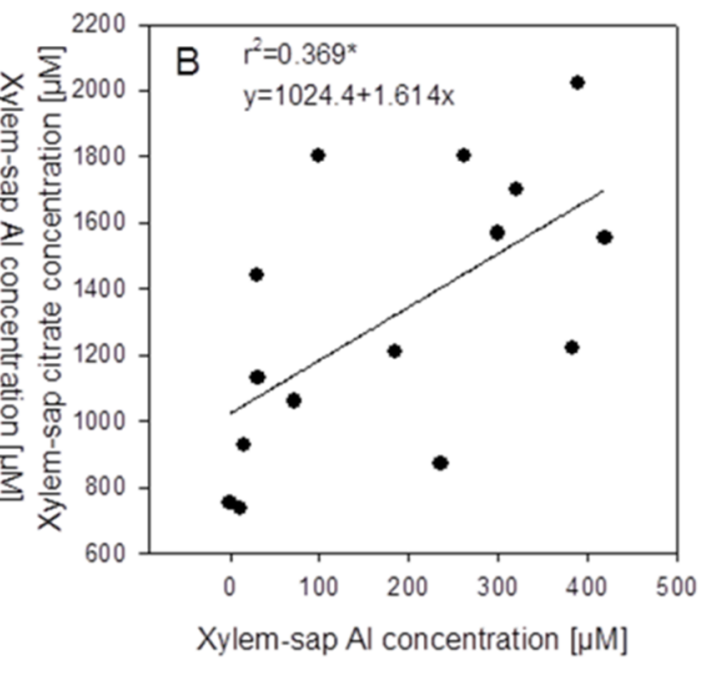

Figure 3. Primary leaf and xylem-sap Al concentrations of buckwheat $c v$. "Lifago" plants as affected by increasing $\mathrm{Al}_{2}\left(\mathrm{SO}_{4}\right)_{3} \cdot 18 \mathrm{H}_{2} \mathrm{O}$ supply to the substrate, three weeks after germination (A), and relationship between xylem-sap Al and citrate concentrations (B). Bars represent means $\pm \mathrm{SE}, n=3$. In (A), different capital and lower-case letters denote significant $(p<0.05)$ differences between leaf and xylem-sap Al concentrations, respectively; In (B), ${ }^{* * *}$ denote significance of the regression coefficient at $p<0.001$.

Based on this experiment the whole set of genotypes of the genus Fagopyrum was cultivated at an Al supply of $8 \mathrm{~g} \mathrm{Al}_{2}\left(\mathrm{SO}_{4}\right)_{3} \cdot 18 \mathrm{H}_{2} \mathrm{O}$. The fresh matter production of the 94 genotypes varied between $5 \mathrm{~g}$ and $10 \mathrm{~g}$ per plant after three weeks of cultivation. The number of leaves per plant was particularly 
variable. Some genotypes showed about five times more leaves than others. Since this biased the comparison of the $\mathrm{Al}$ concentrations of the leaves owing to dilution or concentration effects in the analyzed leaf tissue, the xylem-sap Al concentration appeared to be the more suitable parameter for the characterization of the $\mathrm{Al}$ accumulation capacity. The comparison of the xylem-sap Al concentrations reveals a broad genotypic variation (Figure 4). The highest Al concentrations reached about $350 \mu \mathrm{M}$. None of the genotypes showed $\mathrm{Al}$ concentrations lower than $100 \mu \mathrm{M}$ which could have been indicative of Al excluders. Thus all genotypes can be classified as $\mathrm{Al}$ accumulators. However the $\mathrm{Al}$ accumulation capacity differed greatly between the genotypes across and within the Fagopyrum species.

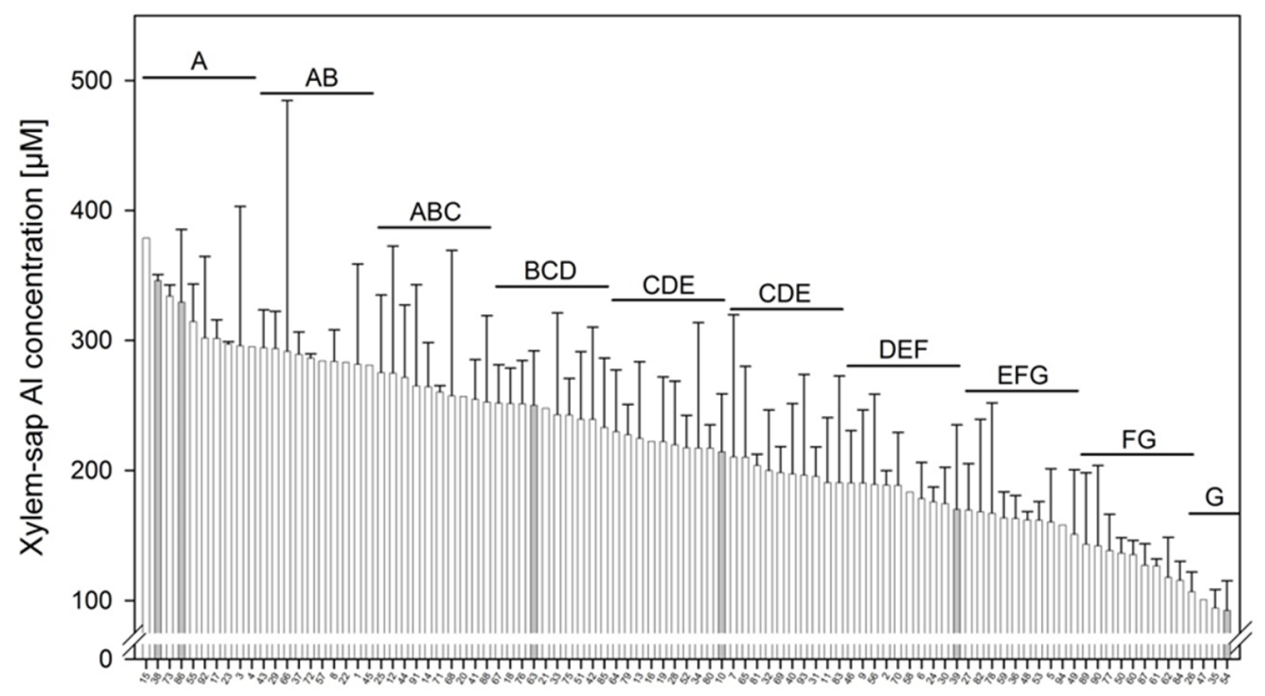

Genotype

Figure 4. Xylem-sap Al concentration of 94 genotypes of the genus Fagopyrum after three weeks of substrate culture with an $\mathrm{Al}$ supply of $8 \mathrm{~g} \mathrm{Al}_{2}\left(\mathrm{SO}_{4}\right)_{3} \cdot 18 \mathrm{H}_{2} \mathrm{O}$. Xylem exudates of three plants per $1 \mathrm{~L}$ pot were combined to one composite sample. Bars represent means $\pm \mathrm{SE}, n=3$. Different letters denote significant differences between Al xylem concentrations at $p<0.05$ (Tukey test).

In the xylem sap not only Al but also citrate and other mineral elements were determined. In spite of high variability of the xylem-sap Al and citrate concentrations, a highly significant positive correlation between the $\mathrm{Al}$ and citrate concentrations across the genotypes existed (Figure 5A). The mean xylem-sap citrate-concentration was 10 times higher than the Al concentration. Among all mineral elements determined in the xylem sap, only Fe was highly significantly positively correlated with the $\mathrm{Al}$ concentration (Figures 5B and S2). The mean Fe xylem-sap concentration was 10 times lower than the Al concentration. Also citrate and Fe xylem-sap concentrations were highly significantly positively correlated ( $p<0.001$, Figure S3). However, the slope of the regression suggests that on average across genotypes, 93 times more citrate than Fe was loaded into the xylem.

For a further in-depth study in hydroponics, six F. esculentum genotypes (grey columns in Figure 4) were selected on the basis of significantly different xylem-sap Al concentrations. In the hydroponic system the ranking of the genotypes for $\mathrm{Al}$ accumulation based on the screening in substrate could only partially be confirmed: the genotypes 38 and 86 proved to be more efficient Al accumulators than 
the genotypes 63 and 10 based on high xylem (Figure 6A) and leaf (Figure 6B) Al concentrations. However, the genotypes 54 and 39 with the lowest xylem Al concentrations in the substrate experiment had equally high $\mathrm{Al}$ accumulation capacity compared to the genotypes 38 and 86 . This indicates that the conditions in the substrate and the hydroponic experiment differed greatly with regard to form and concentration of plant-available Al.
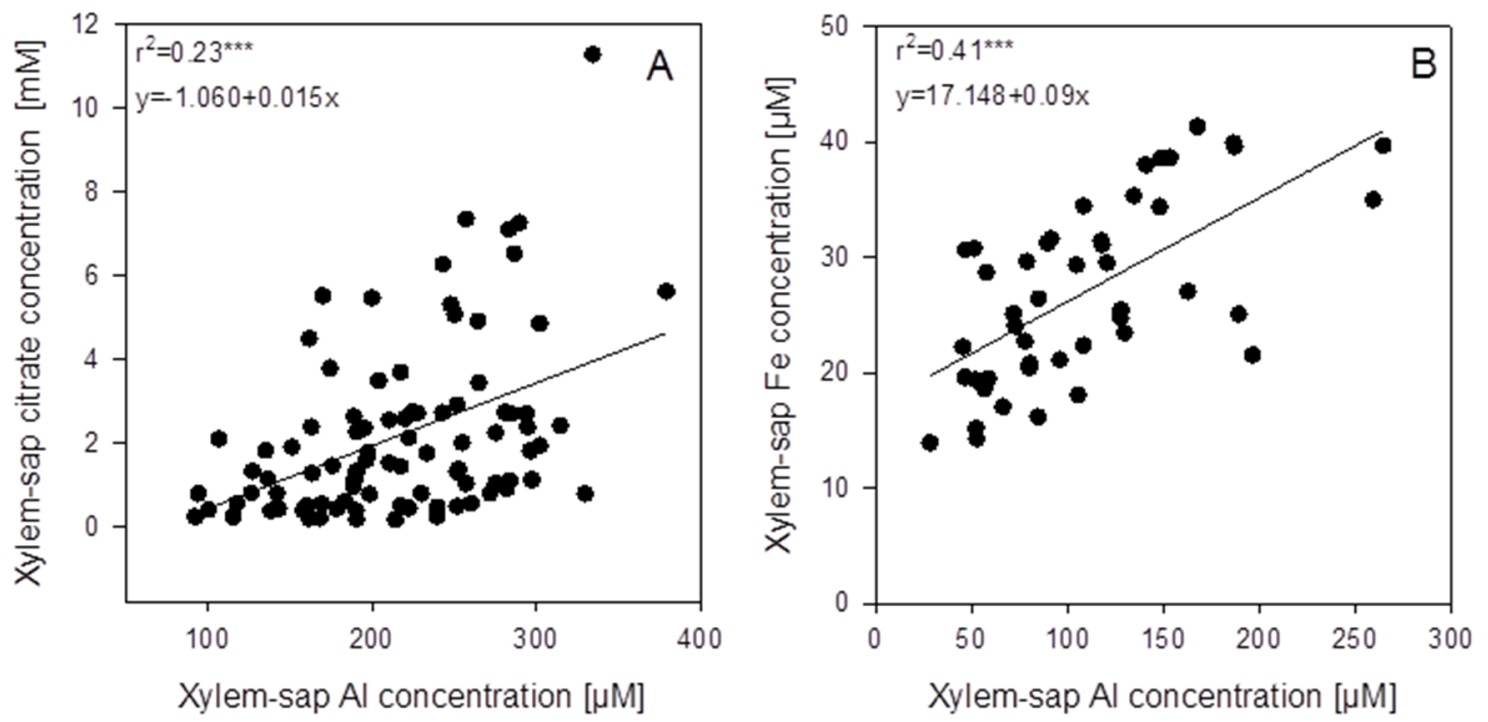

Figure 5. Correlations between xylem-sap Al concentrations and the xylem-sap citrate (A) and iron (B) concentrations of 94 (A) or 46 (B) genotypes of the genus Fagopyrum after 3 weeks of substrate culture with an Al supply of $8 \mathrm{~g} \mathrm{Al}_{2}\left(\mathrm{SO}_{4}\right)_{3} \cdot 18 \mathrm{H}_{2} \mathrm{O}$. Xylem sap was collected for 30 min after cutting off the shoots. Points represent means $\pm \mathrm{SE}, n=3$. $* * *$ denote significance of the regression coefficient at $p<0.001$.
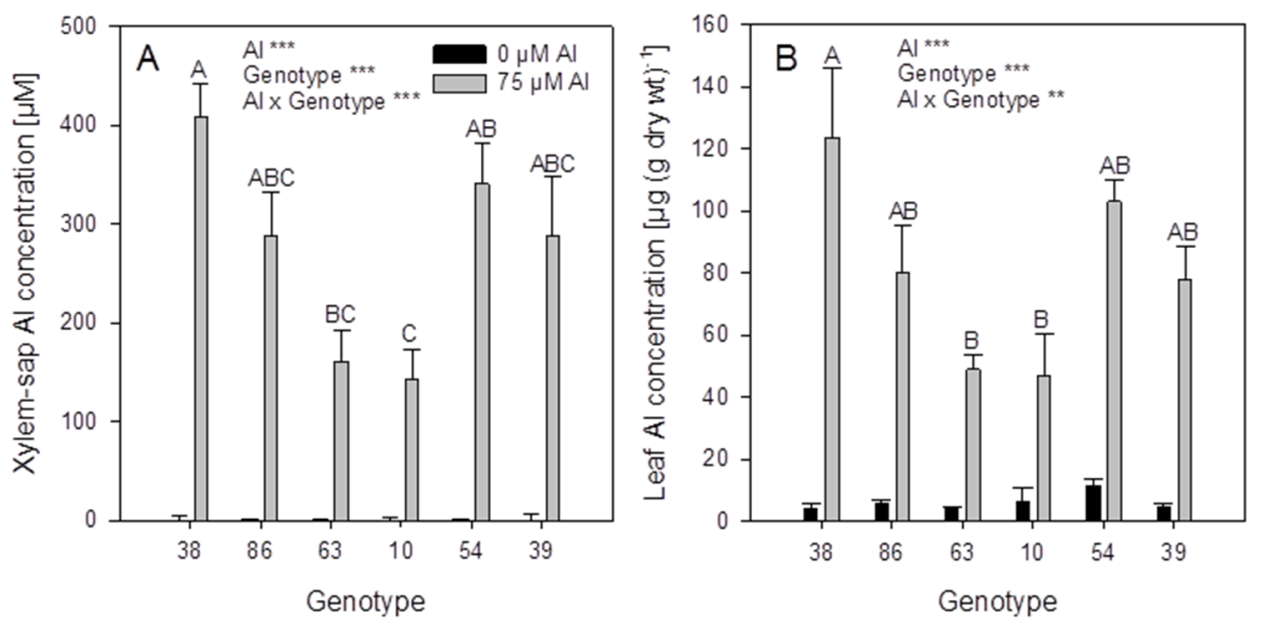

Figure 6. Xylem-sap (A) and leaf (B) Al concentrations of six selected Fagopyrum esculentum genotypes. Plants were pre-cultured in complete nutrient solution and then transferred for $24 \mathrm{~h}$ to simplified nutrient solution without or with $75 \mu \mathrm{M}$ Al. Bars represent means $\pm \mathrm{SE}, n=3$. For the ANOVA, $* *$ and $* * *$ denote significant effects at $p<0.01$ and $p<0.001$, respectively. 
Al treatment significantly reduced the Fe concentrations in the roots (Figure 7A) and even more in the xylem-sap (Figure 7B). The genotypes differed significantly in both, root and xylem-sap Fe concentrations, however, they responded comparably to Al treatment (no Al/genotype interaction). In spite of the clear negative effect of Al supply on the Fe root and xylem-sap concentrations the $\mathrm{Al}$ and $\mathrm{Fe}$ concentrations were highly significantly positively correlated across genotypes and $\mathrm{Al}$ treatments (Figure 8) as in the substrate experiment (see above Figure 5B).
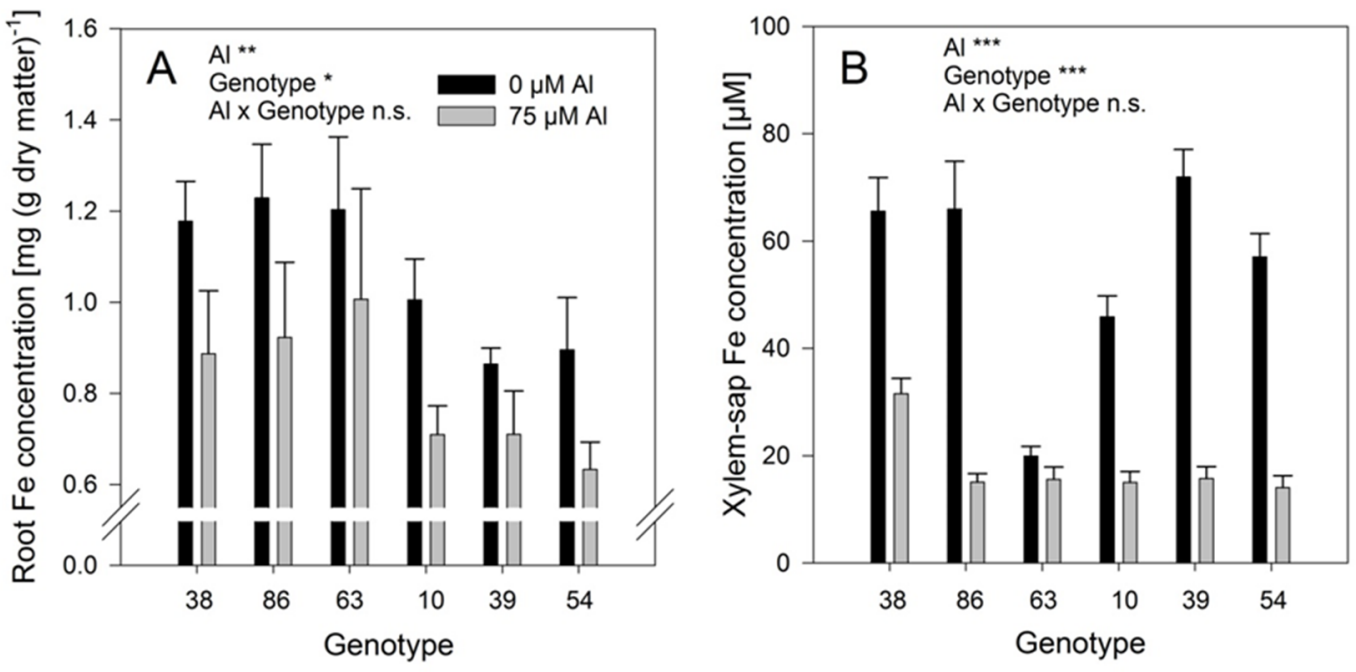

Figure 7. Iron concentrations of the bulk-root dry matter (A) and xylem-sap Fe concentrations (B) of six selected Fagopyrum esculentum genotypes as affected by Al supply. Plants were pre-cultured in complete nutrient solution containing at $60 \mu \mathrm{M}$ Fe-EDDHA and then transferred for $24 \mathrm{~h}$ to simplified nutrient solution without or with $75 \mu \mathrm{M}$ Al. Bars represent means $\pm \mathrm{SE}, n=3$. For the ANOVA, *,**, and *** denote significant effects at $p<0.05,0.01$ and 0.001 , respectively, n.s. non-significant.

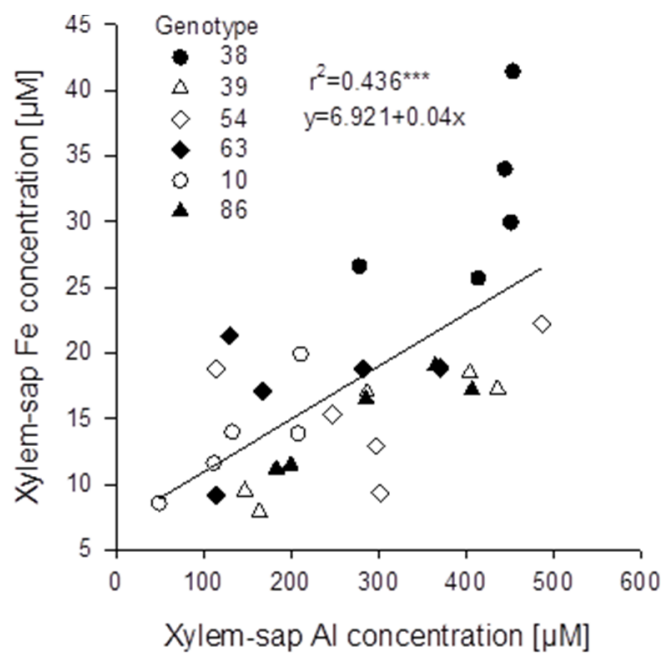

Figure 8. Relationship between xylem-sap $\mathrm{Al}$ and $\mathrm{Fe}$ concentrations of six selected Fagopyrum esculentum genotypes $(n=5)$. Plants were pre-cultured in complete nutrient solution containing $60 \mu \mathrm{M}$ Fe-EDDHA and then transferred for $24 \mathrm{~h}$ to simplified nutrient solution without or with $75 \mu \mathrm{M} \mathrm{Al}$. *** denote significance of the regression coefficient at $p<0.001$. 
The root-growth rates of the controls not treated with Al were in the range of $0.7-1 \mathrm{~mm} \cdot \mathrm{h}^{-1}$ (Figure 9A). Aluminium supply $(75 \mu \mathrm{M})$ decreased the root growth in some genotypes. The genotypes 38, 86, and 63 showed no root-growth inhibition (thus can be classified as Al-resistant), while the genotypes 10, 39, and 54 were inhibited by 30\%-50\% (thus can be classified as Al-sensitive).
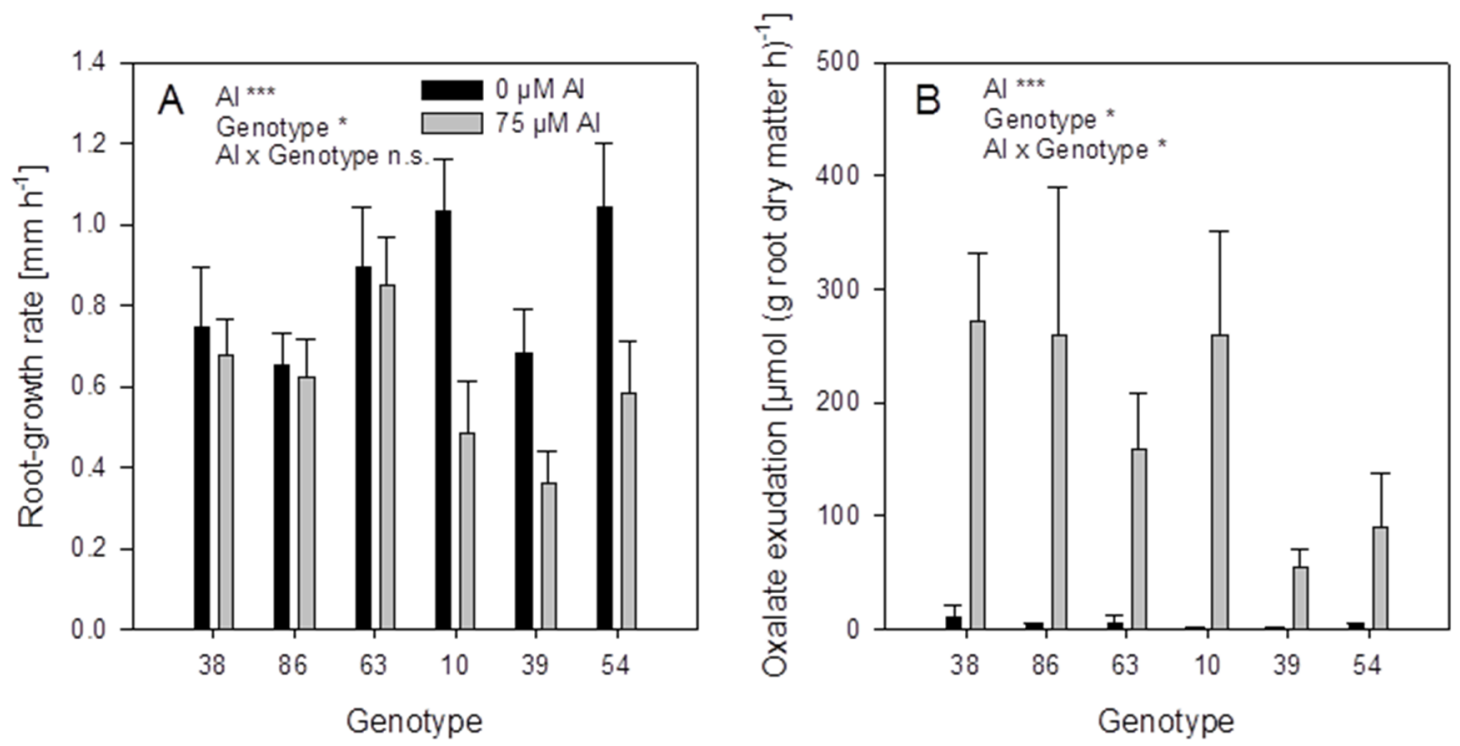

Figure 9. Root-growth rate (A) and oxalate exudation-rate (B) of six selected buckwheat cultivars. Plants were pre-cultured in complete nutrient solution and then transferred for $24 \mathrm{~h}$ to simplified nutrient solution without or with $75 \mu \mathrm{M}$ Al. Root growth-rate was determined by marking the root $15 \mathrm{~mm}$ behind the tip before the treatment and measuring the distance again after $24 \mathrm{~h}$. Root oxalate exudation rate was determined during the first $4 \mathrm{~h}$ of $\mathrm{Al}$ treatment. Bars represent means $\pm \mathrm{SE}, n=3$. For the ANOVA, *,** and *** denote significant effects at $p<0.05,0.01$ and 0.001 , respectively.

Root oxalate exudation, was significantly activated by Al application in all genotypes (Figure 9B). Citrate was exuded in minor amounts and showed no Al-activated exudation pattern). The Al-resistant genotypes 38 and 86 showed significantly higher oxalate exudation rates than the Al-sensitive genotypes 39 and 54. However, the genotypes 63 and 10 showed lower or higher oxalate exudation-rates, respectively, than could be expected from their Al resistance classification.

\section{Discussion}

The main focus of this study was to determine differences in Al accumulation in the shoots among a large number of genotypes across three Fagopyrum species. The comparison revealed that all tested species and genotypes accumulated Al in the shoot, thus no qualitative differences were found. In a recent study comparing $\mathrm{Al}$ tolerance and $\mathrm{Al}$ accumulation of three Fagopyrum species (F. esculentum, F. tataricum, F. homotropicum) reference [27] also concluded that Al accumulation is a conserved trait in Fagopyrum. However, there were significant quantitative differences in Al accumulation capability. Genotypes differed in xylem Al concentration by a factor of about four (Figure 4). The xylem-sap Al concentration was chosen as the primary parameter for the comparison of the genotypes for Al accumulation capacity. The xylem sap was sampled after only $0.5 \mathrm{~h}$, because various studies 
showed that only shortly after cutting of the shoot representative data on the in vivo xylem-sap composition can be assessed [27]. Moreover, the same technique has been used for the characterization of heavy metal hyper-accumulation. Xylem-sap $\mathrm{Cd}$ and $\mathrm{Zn}$ concentrations were used to show a considerable scope for the selection of advanced-hyper-accumulating ecotypes with the objective of increasing phyto-extraction efficiency and remediation of metal-contaminated soils [28]. The Al-accumulation trait could not be related to the geographic origin of the genotypes. The genotypes with the highest $\mathrm{Al}$ concentration in the xylem sap originate from different regions as for example Belarus (genotype 15), Iran (genotype 38), North Korea (genotype 73), and Italy (genotype 86).

A similar range of quantitative differences in $\mathrm{Al}$ accumulation has also been found within the family of Melastomataceae [29]. Species from this family accumulated Al in great amounts in the shoot. However, the variation within the family was shown to be in the range of 6-66 $\mathrm{mg} \mathrm{Al} \cdot \mathrm{g}^{-1}$ dry matter. In contrast, a comparison of members of the taxa Polygonaceae, of which the genus Fagopyrum is a member, showed that some species differing in Al resistance did not accumulate Al in their shoots [30]. This might suggest that the trait of $\mathrm{Al}$ accumulation is not spread over the whole family of the Polygonaceae and is rather typical for the genus Fagopyrum. Here, this genus showed only quantitative but not qualitative differences in $\mathrm{Al}$ accumulation. Based on semi-quantitative tests reference [29], mapped a recent angiosperm phylogeny for the trait of Al accumulation. As indicated by references [15,31] this classification might suggest that Al hyper-accumulation is a simple, primitive trait that has arisen independently several times during evolution but was lost independently in many derived taxa. These authors suggest that the trait of $\mathrm{Al}$ accumulation shows low incidence in evolutionary advanced groups which appeared to be correlated with the herbaceous habit. Therefore, the herbaceous genus Fagopyrum might represent an exceptional case.

An unexpected result of the study was the confirmation of an interrelationship between $\mathrm{Al}$ and $\mathrm{Fe}$ transport in buckwheat. Across all Fagopyrum genotypes studied xylem-sap Al and Fe concentrations were highly significantly positively correlated (Figure 5B). A similar relationship could also be found in the hydroponic experiment with six selected F. esculentum genotypes (Figure 8). This was unexpected, because Al supply strongly reduced root Fe concentrations (Figure 7A) and xylem-sap Fe concentrations (Figure 7B). Since during the $24 \mathrm{~h} \mathrm{Al}$ treatment period in simplified nutrient solution no Fe was applied, this cannot be explained by inhibition of Fe uptake by Al. It rather appears that the Al-induced release of oxalate from the root ([18], Figure 9B) mobilizes apoplastically immobilized Fe. It has been reported that a large amount of Fe may be bound in the root apoplast which may be mobilized under conditions of Fe deficiency through $\mathrm{Fe}$ deficiency-induced release of $\mathrm{Fe}$ complexors [32]. However, the mobilization of apoplastic Fe during the Al treatment period did not lead to higher Fe uptake and translocation in the xylem. It thus appears that Fe-oxalate is not readily taken up and loaded into the xylem, where, in fact, Fe is transported as citrate complex [33,34].

Using NMR, reference [35] showed that in buckwheat also Al is complexed and detoxified by citrate anions in the xylem sap, and reference [23] confirmed the dominance of Al-citrate as the main Al transport form not only in F. esculentum but also in $F$. tataricum and the wild buckwheat $F$. homotropicum. In the study by reference [35] the xylem citrate-concentration did not respond to externally applied or internally transported Al. These results are in agreement with the analysis of the effect of $\mathrm{Al}$ on the global transcriptome in F. esculentum [36] and F. tataricum [37] root tips which did not show major effects on genes involved in organic acid metabolism suggesting that citrate was not a 
rate-limiting step for $\mathrm{Al}$ transport into and in the xylem. However, in these studies a major difference in citrate concentration and synthesis between the root cortex and the central cylinder has not been taken into consideration. This assumption is supported by own data on the oxalate and citrate contents in surgically partitioned cortical and stele tissues [25]. In contrast, in our study a significant positive correlation between xylem-sap citrate and Al concentrations existed when the Al supply to substrate grown buckwheat cultivar Lifago was increased (Figure 3B) and across the Fagopyrum genotypes (Figure 5A) confirming previous results by references [24,25]. Also in the Al accumulator H. macrophylla $\mathrm{Al}$ and citrate xylem-sap concentrations were positively correlated [38]. However, only a low percentage of the variation of the citrate concentration could be explained by the Al concentration $\left(r^{2}=0.23 * * *\right)$, and citrate was more abundant than Al by a factor of ten (Figure $5 \mathrm{~A}$ ). Iron is known to be transported in the xylem coupled to citrate which is loaded into the xylem through MATE/FRD-proteins coded by FRD3 in Arabidopsis [39], OsFRDL1 in rice [40] or HvAACT1 in barley [41]. The above mentioned recent global transcriptome analysis of Al-induced genes in root tips clearly revealed that among the strongly Al up-regulated genes were the homologues of these genes, FtFRDL1 and FtFRDL2 in F. tataricum [37] and FeMATE1 and FeMATE2 in F. esculentum [36]. Their role in citrate and Al loading into the xylem remains to be investigated in the future.

It is particularly important to clarify whether $\mathrm{Al}$ (and Fe) is loaded into the xylem in a co-transport or as the negatively charged Al-citrate complex as has been postulated by reference [25]. It is intriguing that the genotypic differences in xylem-sap $\mathrm{Al}$ concentrations in the presence of $\mathrm{Al}$ are closely related to the Fe concentrations in the absence of $\mathrm{Al}$ (compare Figures 6A and 7B). Together with the strong reduction of Fe xylem-sap concentrations by Al (Figure 7B) this may indicate that both $\mathrm{Al}$ and $\mathrm{Fe}$ are transported through the same transporter, and Fe transport is competitively inhibited by the more abundant Al (factor ten). The positive correlation between xylem-sap $\mathrm{Al}$ and $\mathrm{Fe}$ concentrations may then reflect the Al-enhanced transporter abundance in agreement with the higher expression of the genes coding for these transporters [36,37].

The six F. esculentum genotypes selected for differences in Al xylem-sap concentrations also showed great variability in Al-induced root-growth inhibition and thus Al resistance (Figure 9A). The $\mathrm{Al}$-induced root oxalate-exudation is a well-established Al resistance and Al exclusion mechanism (see Introduction). Among the six genotypes Al resistance was highly significantly positively correlated with Al-induced root oxalate-exudation (Table 1). However, oxalate exudation explained only about $50 \%$ of the variation in $\mathrm{Al}$ resistance. Also shoot $\mathrm{Al}$ accumulation was highly significantly correlated with $\mathrm{Al}$ resistance indicating that $\mathrm{Al}$ accumulation and $\mathrm{Al}$ tolerance also contribute to overall Al resistance of buckwheat as has been suggested by reference [25]. Evaluating the role of both oxalate exudation and $\mathrm{Al}$ accumulation in $\mathrm{Al}$ resistance using multiple regression analysis (Table 1) revealed that more than $70 \%\left(r^{2}=0.725 * * *\right)$ of the variation in Al-induced root-growth inhibition can be explained by these two variables. It thus appears that both $\mathrm{Al}$ exclusion by oxalate root-exudation and rapid oxalate-facilitated $\mathrm{Al}$ uptake and citrate-facilitated Al translocation to the shoot are involved in the protection of the root-tip apoplast, the main target of $\mathrm{Al}$ rhizotoxicity as elaborated by reference [42]. The genes and proteins (particularly transporters involved in Al exclusion and Al tolerance/accumulation) have still not yet been identified. It is expected that recent transcriptomic studies will pave the way for a better understanding of the molecular basis of Al resistance of buckwheat $[36,37,43]$. In the model plants Arabidopsis and rice, an interplay between Al exclusion by 
root exudation of organic acid anions and the rapid uptake and accumulation in the root vacuole has been widely established $[17,44]$. However, these plant species do not translocate Al to the shoots, a typical feature of $\mathrm{Al}$ accumulators such as Fagopyrum.

Table 1. Regression analysis of the relationships between relative root-growth rate $(75 \mu \mathrm{M}$ Al supply for $24 \mathrm{~h}$ in simplified nutrient solution compared to the $0 \mu \mathrm{M}$ Al control) and root oxalate exudation or/and leaf Al concentration of six $F$. esculentum genotypes. *** denote the level of significance.

\begin{tabular}{llcc}
\hline \multicolumn{1}{c}{ Variable parameters } & \multicolumn{1}{c}{ Function of the regression } & $\boldsymbol{r}^{2}$ & $\boldsymbol{p}$ value \\
\hline $\begin{array}{l}\text { Oxalate exudation } v s . \text { relative } \\
\text { root-growth rate }\end{array}$ & $y=37.09+0.19 x$ & 0.538 & $<0.001^{* * *}$ \\
\hline $\begin{array}{l}\text { Leaf Al accumulation } v s . \text { relative } \\
\text { root-growth rate }\end{array}$ & $y=-23.14+0.7 x$ & 0.485 & $<0.001 * * *$ \\
\hline $\begin{array}{l}\text { Multiple regression: } \\
\begin{array}{l}\text { Oxalate exudation and leaf Al accumulation } \\
v s . \text { relative root-growth rate }\end{array}\end{array}$ & $\begin{array}{l}y=-18.534+(0.139 \cdot \text { oxalate exudation }) \\
+(0.480 \text { leaf Al accumulation })\end{array}$ & 0.725 & $<0.001 * * *$ \\
\hline
\end{tabular}

\section{Experimental Section}

\subsection{Plant Material}

The screening experiments were conducted using a reference cultivar of buckwheat (Fagopyrum esculentum Moench $c v$. "Lifago") known from former experiments (Klug and Horst, 2010a, b and c) which was provided by Deutsche Saatveredelung AG (Lipstadt, Germany). Additionally, a set of 94 Fagopyrum accessions was kindly provided by the gene bank of the Leibniz Institute of Plant Genetics and Crop Plant Research (IPK, Gatersleben, Germany). These Fagopyrum accessions included primarily genotypes of $F$. esculentum Moench var. esculentum (76); F. esculentum Moench var. Emarginatum (Roth) Alef. (5); F. tataricum (L.) Gaertn (13), and F. acutatum (Lehm.) Mansf. ex Hammer (1). The overall genetic origin of these genotypes is spread over Europe and Asia (Table S1). For the subsequent in-depth analysis of $\mathrm{Al}$ resistance mechanisms in hydroponics, genotypes with differing Al translocation patterns according to the screening experiment were chosen from the species F. esculentum Moench esculentum.

\subsection{Plant Cultivation}

\subsubsection{Pot Experiments}

For the main pot experiment, plants were sown into peat-based substrate containing $30 \%$ clay without the addition of $\mathrm{Al}$ avoiding $\mathrm{Al}$ toxicity during the process of germination. In the following 3 weeks of cultivation $\mathrm{Al}$ was added in 4 steps each consisting of supplies of $2 \mathrm{~g} \mathrm{Al}_{2}\left(\mathrm{SO}_{4}\right)_{3} \cdot 18 \mathrm{H}_{2} \mathrm{O}$ $(162 \mathrm{mg} \mathrm{Al})$ resulting in a total supply of $8 \mathrm{~g}$ of $\mathrm{Al}_{2}\left(\mathrm{SO}_{4}\right)_{3} \cdot 18 \mathrm{H}_{2} \mathrm{O}(648 \mathrm{mg} \mathrm{Al})$ per L substrate. This $\mathrm{Al}$ amount was based on a substrate specific Al-buffer curve with a target $\mathrm{pH}$ of the aqueous substrate extract of 4.3, as recommended for the production of blue-colored Hydrangea macrophylla [38]. 
The reference $F$. esculentum variety "Lifago" was additionally exposed to different $\mathrm{Al}$ concentrations $\left(0 ; 2 ; 4 ; 6\right.$, and $8 \mathrm{~g}$ of $\mathrm{Al}_{2}\left(\mathrm{SO}_{4}\right)_{3} \cdot 18 \mathrm{H}_{2} \mathrm{O}$ corresponding to $162,324,486$, and $648 \mathrm{mg} \mathrm{Al}$, respectively, per L substrate) to evaluate the response of the plants to increasing Al supply. Three plants were grown in each pot, containing $1 \mathrm{~L}$ of substrate for 21 days. Plant tissue and xylem exudate samples of these three plants were combined to one composite sample. The experimental design was a randomized block design with three replications. Plants were grown in a greenhouse at natural light intensity and day length and $20 / 18{ }^{\circ} \mathrm{C}$ day and night temperatures, respectively. Plants were fertilized once a week with $100 \mathrm{~mL}$ of a $30 \mathrm{~g} \cdot \mathrm{L}^{-1}$ solution of a commercial phosphorus-free fertilizer containing $18 \% \mathrm{~N}, 18.3 \%$ K., $2 \% \mathrm{Mg}, 0.02 \% \mathrm{~B}, 0.04 \% \mathrm{Cu}, 0.1 \% \mathrm{Fe}, 0.05 \% \mathrm{Mn}, 0.01 \% \mathrm{Mo}$, and $0.01 \% \mathrm{Zn}$.

\subsubsection{Nutrient Solution Experiments}

F. esculentum genotypes differing in $\mathrm{Al}$ accumulation were chosen for further investigations in a nutrient solution experiment. Selected F. esculentum genotypes were germinated for 7 days in a foam filter-paper sandwich-system. After germination the seedlings were transferred to low ionic-strength nutrient solution with the following composition $(\mu \mathrm{M}): 500 \mathrm{KNO}_{3}, 162 \mathrm{MgSO}_{4}, 30 \mathrm{KH}_{2} \mathrm{PO}_{4}, 250$ $\mathrm{Ca}\left(\mathrm{NO}_{3}\right)_{2}, 8 \mathrm{H}_{3} \mathrm{BO}_{3}, \quad 0.2 \quad \mathrm{CuSO}_{4}, 0.2 \quad \mathrm{ZnSO}_{4}, 5 \quad \mathrm{MnSO}_{4}, 0.2\left(\mathrm{NH}_{4}\right)_{6} \mathrm{Mo}_{7} \mathrm{O}_{24}, 50 \mathrm{NaCl}$, and $30 \mathrm{Fe}-\mathrm{EDDHA}$. The seedlings were grown for 2 weeks in nutrient solution. Afterwards, the $\mathrm{pH}$ of the nutrient solution was reduced in three steps to 4.3 resulting in at least $12 \mathrm{~h}$ for adaptation to the low $\mathrm{pH}$ before the beginning of the $\mathrm{Al}$ treatment $( \pm 75 \mu \mathrm{M} \mathrm{AlCl} 3$ at $\mathrm{pH} 4.3)$ in minimal nutrient solution, containing $500 \mu \mathrm{M} \mathrm{CaCl}_{2}, 100 \mu \mathrm{M} \mathrm{K}_{2} \mathrm{SO}_{4}$ and $8 \mu \mathrm{M} \mathrm{H}_{3} \mathrm{BO}_{3}$ to avoid mineral interactions during the short-term $\mathrm{Al}$ treatment.

\subsection{Substrate Analysis}

The $\mathrm{pH}$, and the concentration of soluble total and monomeric $\mathrm{Al}$ and mineral nutrients in the substrate were determined in a 1:3 water extract after 1 day incubation of the substrate at room temperature. The extracts were passed through a filter with a pore size of $0.45 \mu \mathrm{m}$. Al and mineral nutrients were determined by optical inductively coupled plasma-emission spectroscopy (ICP-OES) (Spectro Analytical Instruments $\mathrm{GmbH}$, Kleve, Germany). Monomeric Al concentration was determined following the method of [45] using aluminon. The extinction of the Al-aluminon complex was spectrophotometrically measured at $532 \mathrm{~nm}$.

\subsection{Sampling of Xylem Sap}

Sampling of xylem sap was performed following the method described by Ma and Hiradate (2000) with some modifications. The stem was severed $2 \mathrm{~cm}$ above the root and the xylem sap was collected for not more than $0.5 \mathrm{~h}$ to yield reliable data on in vivo concentrations of solutes in the xylem sap. The cut surface was rinsed with double distilled water $\left(\mathrm{ddH}_{2} \mathrm{O}\right)$ and blotted off. The xylem sap was collected in $1 \mathrm{~mL}$ micro-pipette tips which were trimmed to fit the cut stem. The volumes of the exudates were determined by $1000 \mu \mathrm{L}$ micropipettes. Exudates were immediately frozen in liquid $\mathrm{N}_{2}$. 


\subsection{Measurement of Root Elongation Rate}

Plants were pre-cultured in complete nutrient solution and then transferred for $24 \mathrm{~h}$ to simplified nutrient solution with or without $75 \mu \mathrm{M}$ Al. Root growth-rate was determined by marking the root tips with Plaka color (Pelikan, Feusisberg, Switzerland) using a fine paint brush $15 \mathrm{~mm}$ behind the tip before the treatment and measuring the distance again after $24 \mathrm{~h}$.

\subsection{Collection of Root Exudates}

For collection of root exudates adventitiously rooted cuttings were produced as follows: Plants were grown for 4 weeks in a green house at $25 / 20{ }^{\circ} \mathrm{C}$ day/night temperature. After this period of growth the shoots were cut $1 \mathrm{~cm}$ below the first node with adventitious root initials and additionally above the primary leaf to reduce transpiration. These shoot cuttings were transferred to low ionic strength nutrient solution with the following composition $[\mu \mathrm{M}]: 500 \mathrm{KNO}_{3}, 162 \mathrm{MgSO}_{4}, 30 \mathrm{KH}_{2} \mathrm{PO}_{4}, 250$ $\mathrm{Ca}\left(\mathrm{NO}_{3}\right)_{2}, \quad 8 \mathrm{H}_{3} \mathrm{BO}_{3}, \quad 0.2 \quad \mathrm{CuSO}_{4}, 0.2 \quad \mathrm{ZnSO}_{4}, 5 \quad \mathrm{MnSO}_{4}, 0.2 \quad\left(\mathrm{NH}_{4}\right)_{6} \mathrm{Mo}_{7} \mathrm{O}_{24}, 50 \mathrm{NaCl}$, and $30 \mathrm{Fe}$-EDDHA for 4 days keeping the shoots at $100 \%$ relative humidity $(\mathrm{rH})$ until adventitious roots had emerged. The following day the plants were adapted to lower $\mathrm{rH}$ by reducing air humidification. Another day later the $\mathrm{pH}$ of the nutrient solution was reduced in three steps resulting in at least $12 \mathrm{~h}$ for adaptation to $\mathrm{pH} 4.3$ before the beginning of the $\mathrm{Al}$ treatment. Afterwards, the plants were transferred to $10 \mathrm{~mL}$ of a simplified continuously aerated nutrient solution $\left(500 \mu \mathrm{M} \mathrm{CaCl}_{2}, 8 \mu \mathrm{M} \mathrm{H}_{3} \mathrm{BO}_{3} ; 100 \mu \mathrm{M}\right.$ $\mathrm{K}_{2} \mathrm{SO}_{4}, \mathrm{pH} 4.3$ ) supplemented either with $0 \mu \mathrm{M}$ or $75 \mu \mathrm{M} \mathrm{AlCl} 3$ inhibiting root growth by $50 \%-60 \%$ (Klug and Horst, 2010b) and activating Al exclusion and tolerance mechanisms [24]. The pH was controlled frequently and, when necessary, re-adjusted to 4.3 using $0.1 \mathrm{M} \mathrm{HCl}$ or $0.1 \mathrm{M} \mathrm{KOH}$.

\subsection{Mineral Element Analysis}

Mineral element contents in the bulk-leaf tissue were determined in the primary leaf after dry ashing at $480{ }^{\circ} \mathrm{C}$ for $8 \mathrm{~h}$, dissolving the ash in concentrated 1:3 diluted $\mathrm{HNO}_{3}$, and then diluting $(1: 10 v / v)$ with $\mathrm{ddH}_{2} \mathrm{O}$. Measurements were carried out by inductively coupled plasma-emission mass spectrometry (ICP-OES, 7500 CX, Agilent Technologies, Santa Clara, CA, USA). The Al concentration in the xylem sap was determined after appropriate dilution with $\mathrm{ddH}_{2} \mathrm{O}$ by graphite furnace atomic absorption spectrometry (GF-AAS) (Unicam 939 QZ, Analytical Technologies, Cambridge, UK). The composition of other mineral elements in the xylem sap was determined after dilution by ICP-OES.

\subsection{Determination of Organic Acids}

The organic acid (OA) concentrations of the root exudates as well as the xylem sap were measured by isocratic High Pressure Liquid Chromatography (HPLC, Kroma System 3000, Kontron Instruments, Munich, Germany). The OAs were injected through a $20 \mu \mathrm{L}$ loop-injector (Auto-sampler $360)$ of the HPLC, separating different OAs on an Animex HPX-87H $(300 \times 7.8 \mathrm{~mm})$ column (BioRad, Laboratories, Richmond, CA, USA), supplemented with a cation $\mathrm{H}^{+}$micro-guard cartridge, using $10 \mathrm{mM}$ perchloric acid as eluent at a flow rate of $0.5 \mathrm{~mL}$ per minute, at a constant temperature of $35{ }^{\circ} \mathrm{C}$ (Oven 480 ), and $74 \mathrm{hPa}$ of atmospheric pressure. Measurements were performed at a wavelength 
$\lambda=214 \mathrm{~nm}$ (UV Detector 320). Prior to the analysis of exuded OA the nutrient solution samples run through a cation exchange-column (hydrochloric form) (AG ${ }^{\circledR} 50 \mathrm{~W}-\mathrm{X} 8$; BioRad; Life Science Group; Hercules, CA, USA) followed by concentration to dryness using a centrifugal evaporator (RCT 10-22T, Jouan,Saint-Herblain, France).

\section{Conclusions}

The screening in Al-enriched peat substrate of 94 accessions within the genus Fagopyrum suggested that $\mathrm{Al}$ accumulation is a conserved trait in Fagopyrum and no qualitative but quantitative differences existed between the accessions. A correlation between $\mathrm{Al}$ and citrate and $\mathrm{Fe}$ concentrations in the xylem sap which could be confirmed in a nutrient solution experiment with selected $F$. esculentum genotypes suggest that $\mathrm{Fe}$ and $\mathrm{Al}$ are loaded into and transported in the xylem through related mechanisms involving citrate. This is in agreement with recent global transcriptomic analysis showing major up-regulation by $\mathrm{Al}$ of citrate transporters. The mechanism of citrate-enhanced Al loading into the xylem remains to be elucidated. The significant relationships between oxalate root-exudation and $\mathrm{Al}$ accumulation in the shoot suggest that $\mathrm{Al}$ exclusion from the root and rapid Al uptake and loading into the xylem both contribute to the protection of the root apoplast from Al injury and thus Al resistance in Fagopyrum. The recent progress through global transcriptome analysis of Al-induced genes will allow further characterization of $\mathrm{Al}$ resistance and $\mathrm{Al}$ accumulation in buckwheat in the near future. However many of the related genes are constitutively expressed in buckwheat requiring the availability of isolines/mutants lacking the $\mathrm{Al}$ exclusion/Al accumulation phenotypes.

\section{Acknowledgments}

We wish to thank the gene bank of the Leibniz Institute of Plant Genetics and Crop Plant Research and the Deutsche Saatveredelung AG for providing the seeds.

\section{Author Contributions}

Benjamin Klug and Thomas Kirchner conducted the experiments, evaluated and presented the results. Walter Horst initiated the research and provided the necessary research support and guidance. Benjamin Klug and Walter Horst wrote the manuscript with the support of Thomas Kirchner.

\section{Conflict of Interest}

The authors declare no conflict of interest.

\section{References}

1. Von Uexküll, H.R.; Mutert, E. Global extent, development and economic impact of acid soils. Plant Soil 1995, 171, 1-15.

2. Kochian, L.V.; Hoekenga, O.A.; Piñeros, M.A. How do crop plants tolerate acid soils? Mechanisms of aluminum tolerance and phosphorus efficiency. Annu. Rev. Plant Biol. 2004, 55, 459-493. 
3. Eticha, D.; Thé, C.; Welcker, C.; Narro, L.; Staß, A.; Horst, W.J. Aluminium-induced callose formation in root apices: Inheritance and selection trait for adaptation of tropical maize to acid soils. Field Crops Res. 2005, 93, 252-263.

4. Welcker, C.; Thé, C.; Andréaub, B.; De Leon, C.; Parentoni, S.N.; Bernal, J.; Félicité, J.; Zonkeng, C.; Salazar, F.; Narro, L.; et al. Heterosis and combining ability for maize adaptation to tropical acid soils. Crop Sci. 2005, 45, 2405-2413.

5. Kochian, L.V.; Pineros, M.A.; Liu, J.; Magalhaes, J.V. Plant adaptation to acid soils: The molecular basis for crop aluminium resistance. Annu. Rev. Plant Biol. 2015, 66, 571-598.

6. Magalhaes, J.V. How a microbial drug transporter became essential for crop cultivation on acid soils: Aluminium tolerance conferred by the multidrug and toxic compound extrusion (MATE) family. Ann. Bot. 2010, 106, 199-203.

7. Ryan, P.R.; Tyerman, S.D.; Sasaki, T.; Furuichi, T.; Yamamoto, Y.; Zhang, W.H.; Delhaize, E. The identification of aluminium resistance genes provides opportunities for enhancing crop production on acid soils. J. Exp. Bot. 2011, 62, 9-20.

8. Ma, J.F. Role of organic acids in detoxification of aluminum in higher plants. Plant Cell Physiol. 2000, 41, 383-390.

9. Delhaize, E.; Gruber, B.D.; Ryan, P.R. The roles of organic anion permeases in aluminium resistance and mineral nutrition. FEBS Lett. 2007, 581, 2255-2262.

10. Schmohl, N.; Horst, W.J. Pectin methylesterase modulates aluminium sensitivity in Zea mays and Solanum tuberosum. Physiol. Plant. 2000, 109, 419-427.

11. Eticha, D.; Staß, A.; Horst, W.J. Cell-wall pectin and its degree of methylation in the maize root-apex: Significance for genotypic differences in aluminium resistance. Plant Cell Environ. 2005, 28, 1410-1429.

12. Yang, J.L.; Zhu, X.F.; Peng, Y.X.; Zheng, C.; Li, G.X.; Liu, Y.; Shi, Y.Z.; Zheng, S.J. Cell wall hemicellulose contributes significantly to aluminum adsorption and root growth in Arabidopsis. Plant Physiol. 2011, 155, 1885-1892.

13. Zhu, X.F.; Lei, G.J.; Wang, Z.W.; Shi, Y.Z.; Braam, J.; Li, G.X.; Zheng, S.J. Coordination between apoplastic and symplastic detoxification confers plant aluminum resistance. Plant Physiol. 2013, 162, 1947-1955.

14. Ma, J.F.; Chen, Z.C.; Shen, R.F. Molecular mechanisms of Al tolerance in gramineous plants. Plant Soil 2014, 381, 1-12.

15. Jansen, S.; Broadley, M.R.; Robbrecht, E.; Smets, E. Aluminum hyperaccumulation in angiosperms: A review of its phylogenetic significance. Bot. Rev. 2002, 68, 235-269.

16. Metali, F.; Salim, K.A.; Burslem, D.F.R.P. Evidence of foliar aluminium accumulation in local, regional and global datasets of wild plants. New Phytol. 2012, 193, 637-649.

17. Delhaize, E.; Ma, J.M.; Ryan, P.R. Transcriptional regulation of aluminium tolerance genes. Trends Plant Sci. 2012, 17, 341-348.

18. Zheng, S.J.; Ma, J.F.; Matsumoto, H. High aluminum resistance in buckwheat: I. Al-induced specific secretion of oxalic acid from root tips. Plant Physiol. 1998, 117, 745-751.

19. Ma, J.F.; Hiradate, S.; Matsumoto, H. High aluminum resistance in buckwheat: II. Oxalic acid detoxifies aluminum internally. Plant Physiol. 1998, 117, 753-759. 
20. Peng, X.; Yu, L.; Yang, C.; Liu, Y. Genotypic difference in aluminum resistance and oxalate exudation of buckwheat. J. Plant Nutr. 2003, 26, 1767-1777.

21. Yang, J.L.; Zhu, X.F.; Zheng, C.; Zhang, Y.J.; Zheng, S.J. Genotypic differences in Al resistance and the role of cell-wall pectin in $\mathrm{Al}$ exclusion from the root apex in Fagopyrum tataricum. Ann. Bot. 2011, 107, 371-378.

22. Shen, R.; Ma, J.F. Distribution and mobility of aluminium in an Al-accumulator, Fagopyrum esculentum Moench. J. Exp. Bot. 2001, 52, 1683-1687.

23. Wang, H.; Chen, R.F.; Iwashita, T.; Shen, R.F.; Ma, J.F. Physiological characterization of aluminum tolerance and accumulation in tartary and wild buckwheat. New Phytol. 2015, 205, 273-279.

24. Klug, B.; Horst, W.J. Spatial characteristics of aluminium uptake and translocation in roots of buckwheat (Fagopyrum esculentum Moench). Pysiol. Plant. 2010, 139, 181-191.

25. Klug, B.; Horst, W.J. Oxalate exudation into the root-tip water free space confers protection from Al toxicity and allows Al accumulation in the symplast in buckwheat (Fagopyrum esculentum). New Phytol. 2010, 187, 380-391.

26. Klug, B.; Specht, A.; Horst, W.J. Aluminium localization in root tips of the aluminium-accumulating plant species buckwheat (Fagopyrum esculentum Moench). J. Exp. Bot. 2011, 62, 5453-5462.

27. Siebrecht, S.; Tischner, R. Changes in the xylem exudate composition of poplar (Populus tremula x P. alba)-dependent on the nitrogen and potassium supply. J. Exp. Bot. 1999, 50, 1797-1806.

28. Lombi, E.; Zhao, F.J.; McGrath, S.P.; Young, S.D.; Sacchi, G.A. Physiological evidence for a high affinity cadmium transporter highly expressed in a Thlaspi caerulescens ecotype. New Phytol. 2001, 149, 53-60.

29. Jansen, S.; Watanabe, T.; Smets, E. Aluminium accumulation in leaves of 127 species in Melastomataceae, with comments on the order Myrtales. Ann. Bot. 2002, 90, 53-64.

30. You, J.F.; He, Y.F.; Yang, J.L.; Zheng, S.J. A comparison of aluminum resistance among Polygonum species originating on strongly acidic and neutral soils. Plant Soil 2005, 276, 143-151.

31. White, P.J. Al's families: The phylogeny of aluminium accumulation in angiosperms. Trends Plant Sci. 2002, 7, 526.

32. Pavlovic, J.; Samardzic, J.; Maksimović, V.; Timotijevic, G.; Stevic, N.; Laursen, K.H.; Hansen, T.H.; Husted, S.; Schjoerring, J.K.; Liang, Y.; et al. Silicon alleviates iron deficiency in cucumber by promoting mobilization of iron in the root apoplast. New Phytol. 2013, 198, 1096-1107.

33. White, M.C.; Baker, F.D.; Dédaldéchamp, F.; Gaymard, F.; Guerinot, M.; Briat, J.-F.; Curie, C. Metal complexes in xylem fluid: II. Theoretical equilibrium model and computational computer program. Plant Physiol. 1981, 67, 301-310.

34. Tiffin, L.O. Iron translocation I: Plant culture, exudate sampling, iron-citrate analysis. Plant Physiol. 1966, 45, 280-283.

35. Ma, J.F.; Hiradate, S. Form of aluminium for uptake and translocation in buckwheat (Fagopyrum esculentum Moench) Planta 2000, 211, 355-360. 
36. Yokosho, K.; Yamaji, N.; Ma, J.F. Global transcriptome analysis of Al-induced genes in an al-accumulating species, common buckwheat (Fagopyrum esculentum Moench). Plant Cell Physiol. 2014, 55, 2077-2091.

37. Zhu, H.; Wang, H.; Zhu, Y.; Zou, J.; Zhao, F.-J.; Huang, C.-F. Genome-wide transcriptomic and phylogenetic analyses reveal distinct aluminum-tolerance mechanisms in the aluminum-accumulating species buckwheat (Fagopyrum tataricum). BMC Plant Biol. 2015, 15, 16.

38. Naumann, A.; Horst, W.J. Effect of aluminium supply on aluminium uptake, translocation and blueing of Hydrangea macrophylla (Thunb.) Ser. cultivars in a peat-clay substrate. J. Hort. Sci. Biotech. 2003, 78, 463.

39. Durrett, T.P.; Gassmann, W.; Rogers, E.E. The FRD3-mediated efflux of citrate into the root vasculature is necessary for efficient iron translocation. Plant Physiol. 2007, 144, 197-205.

40. Yokosho, K.; Yamaji, N.; Ueno, G.; Mitani, N.; Ma, J.F. OsFRDL1 is a citrate transporter required for efficient translocation of iron in rice. Plant Physiol. 2009, 149, 297-305.

41. Fujii, M.; Yokosho, K.; Yamaji, N.; Saisho, D.; Yamane, M.; Takahashi, H.; Sato, K.; Nakazono, M., Ma, J.F. Acquisition of aluminium tolerance by modification of a single gene in barley. Nat. Commun. 2012, 3, 713.

42. Horst, W.J.; Wang, Y.; Eticha, D. The role of the root apoplast in aluminium-induced inhibition of root elongation and in aluminium resistance of plants: A review. Ann. Bot. 2010, 106, 185-197.

43. Reyna-Llorens, I.; Corrales, I.; Poschenrieder, C.; Barcelo, J.; Cruz-Ortega, R. Both aluminum and $\mathrm{ABA}$ induce the expression of an ABC-like transporter gene (FeALS3) in the Al-tolerant species Fagopyrum esculentum. Environ. Exp. Bot. 2015, 111, 74-82.

44. Li, J.-Y.; Liu, J., Dong, D.; Jia, X., McCouch, S.R.; Kochian, L.V. Natural variation underlies alterations in Nramp aluminum transporter (NRAT1) expression and function that play a key role in rice aluminum tolerance. PNAS 2014, 111, 6503-6508.

45. Kerven, G.L.; Edwards, D.G.; Asher, C.J.; Hallman, P.S.; Kokot, S. Aluminium determination in soil solution. II. Short-term colorimetric procedures for the measurement of inorganic monomeric aluminium in the presence of organic acid ligands. Aust. J. Soil Res. 1989, 27, 91-102.

(C) 2015 by the authors; licensee MDPI, Basel, Switzerland. This article is an open access article distributed under the terms and conditions of the Creative Commons Attribution license (http://creativecommons.org/licenses/by/4.0/). 